\title{
LEARNING FROM ECOFEMINISM: DECONSTRUCTING THE DUALISTIC 'SOFT' VS. 'HARD' NATURE OF ENGINEERING EDUCATION
}

\author{
Robyn Paul, Laleh Behjat, Marjan Eggermont, and Robert Brennan \\ Schulich School of Engineering, University of Calgary \\ rmpaul@ucalgary.ca
}

\begin{abstract}
There has been little progress in increasing the diversity of engineering over the past three and a half decades. Much of the diversity work in engineering has an implicit liberal feminism and fails to deconstruct the hierarchical social categories and the underlying ideals of engineering culture. There is a growing need to critically look at the embedded culture of engineering and how this presents a barrier to diversity.

This paper provides a critical review of key ecofeminist literature and how engineering education can learn from ecofeminist approaches. The ecofeminist framework aims to breakdown dualisms that artificially separate humans and nature, and rather emphasizes the essential interdependence of all organisms.

The aim of this work is to better understand how ecofeminism could be used as a framework to change the culture of engineering education to create a more inclusive environment and foster a greater holistic skillset in our students.
\end{abstract}

Keywords: Ecofeminism : Feminism in engineering : Engineering justice : Social justice

\section{INTRODUCTION}

Our world is facing a significant climate crisis that requires collaborative and cross-disciplinary solutions. Although some might say that as engineers, we are problem solvers and must solve the climate crisis problem, we argue that this elitist view must be dismantled. Rather, our future engineers need to understand we are not solo in this endeavour, and we must work side-by-side with a wide variety and diversity of knowledges. To begin broadening the engineering perspective and deconstructing the culture of engineering towards achieving these goals, we can look internally at our own diversity.

Since the 1950s, women have been considered an underrepresented group in engineering [1]. By 1980, the percentage of women entering engineering rose to just under 20\%, however this number has been stagnant around this level for the past 30 years [2]. Much of the gender research in engineering has an implicit liberal feminism theoretical foundation, where the goal is to ensure equal rights, opportunities, and treatment of women. However, this liberal feminism tends to "universalize white, western, middle class women" [1], and thus fails to deconstruct hierarchical social categories and the underlying ideals. It is evident that the 'women in engineering' approach, although well intentioned, has been disadvantageous to the advancement of gender diversity.

To address this, over the past two decades, there has been increasing research to understand the deeper and fundamental problems about the culture of engineering education and the engineering profession [3]. Researchers have started to critically question how the narratives within engineering education construct and define what is 'engineering' [4]. Classroom research shows that the teaching methods, course content, and attitudes all consistently perpetuate a male-normed culture and are biased against women. Christman sums it up well: "All of these years we have been trying to solve the wrong problem. Women are not broken, but the culture of engineering education is" [5, p. 257].

We need to critically look at the embedded culture of engineering and how this presents a barrier to diversity. An ecofeminist perspective can help to break down these biased cultural norms of engineering. This paper provides a critical review of ecofeminism and suggests key learnings from ecofeminism literature that could be applied to engineering curriculum and culture.

\section{ENGINEERING CULTURE}

In their book EcoJustice Education, Martusewicz, Edmundson and Lupinacci [6] state that "the ecological crisis is really a cultural crisis - that is, a crisis in the way people have learned to think and thus behave in relation to larger life systems and toward each other" (p. 10). Through understanding our own internal engineering culture, we can begin to dismantle these cultural belief systems, beliefs 
which are embedded within decades of technological advances that have led us into the current ecological crisis. In this section, we look at engineering culture and its relationship to engineering education, first through lens of the language of engineering, then through the lens of feminism.

\subsection{The Language of Engineering}

Engineering is often closely associated with 'problem solving'. As well, there is an underlying belief that scientific problem solving is a 'neutral' activity, when in fact, "even the most seemingly neutral technologies" and scientific endeavours "reflect gendered assumptions" [7, p. 8]. Engineering education and problem solving are hierarchical and rooted in a male-normed culture that is not welcoming to minoritized identities [5]. One gendered dualism observed in engineering is the separation of 'hard' skills (i.e., theoretical formulas, mathematical calculations) and 'soft' skills (i.e., sustainability, professional development) [8].

Through classroom observations and interviews, [5] found engineering education has "teaching methods and deeply entrenched beliefs that transmit inherent messages of a hierarchical discourse community, a community that is not friendly to women" (p. X). Faculty members express narratives of engineering that emphasize the "difficulty and elite character of the profession," often wrapped in implications that women and women's work are not a part of this elite brand of engineering [9]. The difficulty and elite culture of engineering was rationalized in faculty members' discourses through a belief that "engineers are critical to society, and such demanding requirements are necessary so only the most capable students can become engineers" [5, p. 253].

Even the language used in STEM syllabi reveals its gendered nature, which is a reflection of professors' ideologies [10]. STEM syllabi promote a culture that is "inherently discriminatory to women and minorities by promoting a view of knowledge as static and unchanging, a view of teaching that promotes the idea of a passive student, and by promoting a chilly climate that marginalizes women" [11, p. 111]. Engineering syllabi tend to promote primarily individual ideologies and goals, with little emphasis towards student personal development [10]. To foster a culture that is inclusive of diverse students, particularly minorities, engineering course curricula must be more reflective of the diversity of their students, and each person's unique experience and learning style.

Scholars have not only brought to light the masculine, elite, and individualistic narratives of engineering, but also that the culture of engineering is often invisible to those who partake in it and continue to promote it. Most faculty are not able to conceptualize the possibility they are upholding this culture of power, privilege and exclusion [5]. Even female students do not "question the profession's central narrative about itself, [rather] the critiques of their marginal status are couched in the dominant ideologies" of engineering culture [12]. Additionally, these perspectives are often challenged because the prominent ideologies of engineering culture, namely depoliticization and meritocracy, make issues of social justice appear irrelevant to engineering practice [13].

As the culture is invisible, it is also understood that it is not always directly intentional. As Austin Channing Brown says in her book I'm Still Here: Black Dignity in a World Made for Whiteness; "When you believe niceness disproves the presence of racism, it's easy to start believing bigotry is rare, and that the label racist should be applied only to mean-spirited, intentional acts of discrimination" $[14$, p. 55]. Male engineering professors and students are nice to their female colleagues and peers, so they feel they must not perpetuate engineering stereotypes, right? Or perhaps their research lab is majority female students, so of course they know how to ensure their learning environment is inclusive? Myself, I'm a queer woman so I must be an exception, I must not promote these dominant ideologies? When in reality, none of us are mean-spirited, but we are all still upholding the discriminatory, masculine, and elite culture of engineering.

\subsection{Feminism in Engineering}

Feminist thought was brought into science by some early scholars including Sandra Harding in 1986 [15] and Donna Haraway in 1988 [16]. Critical feminist theories are powerful in bringing forward the invisible culture discussed above. Feminist pedagogies can observe the hidden curricula in our programs and challenge the dominant assumptions of science and engineering [17]. They make visible "engineering's gendered boundaries," and consider whose identities are excluded from the universal narratives of engineering [3].

Since the 1980 's, the work to promote more women to pursue engineering is based on an assumption of binary masculinity and femininity, and that by targeting women with more information on the variety of career opportunities they will be more likely to choose engineering [18]. Feminist scholars have critiqued this approach and argued that this discourse reinforces the traditional gender norms of engineering and supports the masculine culture of engineering where women are not well-suited for the job [18], [19]. In our attempts to increase diversity of engineering, we placed responsibility onto those who have been excluded, without realizing that they are not the problem, rather the culture of engineering and engineering education is [5]. Additionally, "these persistent notions of gender difference merely illustrate the patriarchal nature of the liberal tradition itself" in which the cis, white, male body is the norm and anything else is considered different and a threat to democracy [19, p. 782].

Bringing discussions around feminism, intersectionality, and postmodern theories is in conflict 
with much of the culture that engineering has built. Beddoes [1] emphasizes this point in her thesis where she documents her efforts to publish three gender theoryinformed articles into engineering education journals around 2010. Through her experience and reflection, she provides a depth of analysis of how to approach feminist theories within an engineering context [1], [20]-[22]. Beddoes' work provides context on pushback this work may encounter, and guidance on how to successfully disseminate feminist work in the field of engineering education.

Although the literature summarized thus far focuses on the gender differences in engineering, it is important to note that any efforts in deconstructing the masculine culture of engineering, must acknowledge the multiple forms of oppression, include race, class, age, ability, and many other factors [3]. Intersectionality is a term first introduced by Kimberly Crenshaw [23] and can be defined as "the interaction between gender, race, and other categories of difference in individual lives, social practices, institutional arrangements, and cultural ideologies and the outcomes of these interactions in terms of power" [24, p. 68]. Within ecofeminist work, bringing in an intersectional perspective is important, as it builds on the oppression of women and nature to further highlight the need to liberate all at the intersectional nodes [25].

\section{ECOFEMINISM}

As with many feminist theories, it is important to keep in mind there is no one definition of ecofeminism and there are strengths to the many diverse perspectives on ecofeminist theory [26]. Simply put, ecofeminism recognizes the connections between the oppression of women and the oppressions of nature. More specifically, at its core, "ecofeminism is the belief that coinciding ecological and feminine repressions are often more than coincidental" [26, p. 11]. Within the ecofeminist theory, there is an understanding of two dualisms at play: male/female and culture/nature [27]. Ecofeminists specifically bring "attention to the associations that have been made between 'woman' and 'nature' which can operate as a source of both subjugation and resistance, exploitation, and inspiration" [28, p. 109].

Within our society there is higher value and power given to male-human-culture relationship than to that of female-biological-nature. The challenge which occurs is that we must not just decouple women from nature, but we must also revalue nature [26]. Our increase in basic scientific literacy such as knowing that atoms make up matter or that matter obeys laws of inertia means that we tend to "see nature as dead and inert, which enables a system of values based on power and domination" [29, p. 121]. It is therefore essential that we promote a stronger integration of the culture-nature connection, and nurture human's ecological connectedness. In this section, we look at ecofeminist theory and its relationship to engineering education from a variety of perspectives: queer theory, understanding and using technology, and examples of social justice pedagogies.

\subsection{Ecofeminism, Dualisms, and Queer Theory}

Queer theory posits that there are many artificial dualisms which exist in our society, often where one side of the dualism is given higher value than the other. Queer theory aims to disrupt binaries, normative processes, definitions, and categories [30]. In the technical discourse of science and engineering particularly, everything is classified into categories, and anything that falls outside these categories is deemed "not normal". Queer theory critiques curriculum to consider broader perspectives, more imaginative possibilities, and to question what counts as knowledge [30].

It is evident that ecofeminist theory also has a queer lens in that it is an examination of "binaries and how those binaries, with their dominant/subordinate assumptions are highly intertwined" [29, p. 120]. Furthermore, the aim of ecofeminism is to "queer the line" between human-nature differences created by the "value-laden universalizing science that puts gender, sex, and sexuality identity into discrete hierarchically stack boxes" [31, p. 952]. Ecofeminism further highlights the need for breaking down the dualistic boundaries that exclude or include certain types of problems, people, and ideas. The next section specifically looks at work that has been done to use principles of ecofeminism to analyze and understand technology.

\subsection{Ecofeminism and Technology}

Scholars have recognized for many decades that "technology is an ecofeminist issue" [32, p. 9]. Ecofeminism can be considered as understanding of the influence that science and technology have on "the relationship between subjectivity and the environment" [29, p. 117]. As designers of technology, we often consider the "users" as inanimate and abstract objects. Whereas, we need to shift this thinking to encompass the needs of the local context in terms of the ecological situation and social group needs [29].

Sustainable technology movements often focus on "wilderness and species preservation, technological solutions, and population control" rather than stressing the importance of "social justice in land, health, education and quality of life" equally across all members of the supply chains [33, p. 230]. The ecofeminist perspective emphasizes the importance of grounding sustainable development movements in social justice, sometimes called "sustainable livelihood," to highlight the need for an approach that considers all living beings of the world. To achieve this, ecofeminism must bring together insights of feminism, technological development, and local perspectives [32, p. 5]. 
Work done by Julia Romberger [29] provides insight into using ecofeminist methodology to investigate technologies. Her work uses an ecofeminist lens to deconstruct the design of Microsoft Word as a word processing technology. Specifically, she outlines six ethical principles for ecofeminist ethnographic research, which she argues can also be applied to non-ethnographic studies. This list is reproduced from Romberger's work [29, p. 126]:

- Inclusion of critical gender analysis

- Promotion of no "isms" of social domination

- Contextualization through acknowledgement of the histories of the subject and researcher

- Recognition of the plurality of perspective

- Rejection of the "abstract individual"

- Recognition of the impact of both material and articulated conditions of the environment on the subject

Her analysis and findings highlight the importance of critically considering the discourse communities and ideologies that are privileged through the technology of MS Word. More importantly, MS Word's design is done under the guise of neutrality and that the technology is designed for individual creativity, when in reality it promotes significant conformity towards homogeneous language, formatting, and grammar of documents. Overall, Romberger uses ecofeminism as a "valuable lens for examining technology with the aim of critical technology literacy in mind" [29, p. 119]. As engineers, ecofeminism can thus be a valuable lens for critically examining engineering designs.

It is important to mention that ecofeminism can be extremely critical of technology. One scholar even went as far to say that technology is the "the essentially villainous agent of the patriarchy" and "the bane of human existence, or that which threatens to destroy all things natural" [34, pp. 4-5]. This viewpoint emphasized the oppression that technology has caused, often to the communities which are already the most marginalized. However, many theorists acknowledge that rather than dismiss technology entirely, we must ensure that it is applied critically, with a wholistic approach that considers the local contexts [29].

\subsection{Social Justice Pedagogies}

Ecofeminist education work within engineering is limited, with only one article using ecofeminism as a framework to analyze the inferior status of sustainability within engineering [8]. However, ecofeminism fits within a broader field of social justice, and there is significant work that has looked at transforming engineering education to be more socially just. Engineering for social justice can be defined as: "engineering practices that strive to enhance human capabilities (ends) through an equitable distribution of opportunities and resources while reducing imposed risks and harms (means) among agentic citizens of a specific community or communities" [35, p. 15]

We can therefore look to social justice work to find examples of application to pedagogies in engineering education classrooms. Here, we will summarize two specific examples.

At Queen's University, a course was developed that aimed to achieve "deconstruction of the 'common sense' of current engineering practices and the creation of alternative practices which are non-oppressive, noncapitalist, and ecologically sustainable" [36, p. 129]. The course was a collaboration between engineering and the social science department, and aimed to better understand the threshold engineers must cross to grasp social justice concepts. The work from these scholars highlights that teaching social justice must use a scaffolded approach, similarly to how we teach any other engineering topic.

At the Colorado School of Mines, an engineering and social justice course aimed to "explore the relationships between engineering and SJ through personal reflection and historical and contemporary case studies" [35, p. 171]. This course provided students with an opportunity to explore engineering ideologies and mindsets in engineering. Students emerged from the course where they now "see themselves as agents with the capacity to engineer to try to even the field for those with less privilege" (p.173). It is evident that by teaching engineering with a social justice approach, we are able to engage students in discussions that will influence how they approach their career as an engineer.

\section{LESSONS FOR ENGINEERING EDUCATION}

This work is the beginnings of a larger project for a $\mathrm{PhD}$ thesis, where the aim is to use ecofeminist best practices to dismantle hidden curricula [37] in engineering. Currently, the work is still in the very early stages, so we want to preface this section by saying, we don't (yet) have the answers. However, through our research and learning process, we can provide some of our insights on what engineering educators might be able to learn from ecofeminist scholars. These are not concrete statements of fact, but rather informed opinions on a way forward. As the reader, we hope you keep this in mind.

\subsection{Acknowledging our value systems}

Ecofeminism is strongly rooted in the idea that our underlying value systems are responsible for interconnected outcomes. Specifically, our society's value of culture-male superiority leads to both the oppression of 
women and the oppression of nature. We cannot solve either of these without first acknowledging the underlying culture-male superiority value system that exists.

In engineering, the value systems are often invisible and we may not realize that they underscore everything we teach. As with much of the research on invisible bias, the first step is recognizing the bias is there. In our engineering classroom discourses, we need to start explicitly acknowledging the implicit value systems we are using. How was the content chosen for the class? Why was this content valued over other content? Who wrote the textbook we are using? What problems are we choosing? What problems are being left out?

Within this context, we must also acknowledge that the value system which underscores much of engineering is the positivistic epistemology, a viewpoint that believes there is one truth in the world, and seeks to find this one truth [38]. In much of what we teach we imply that the positivistic approach is the only way that knowledge can be viewed. Acknowledging this belief in our engineering classes would be an important first step to bringing to light our value systems, and providing opportunities for students to explore other value systems, and different ways of thinking and knowing.

\subsection{Dismantling dualistic thinking}

Within ecofeminism, we understand that often value systems are created based on dualisms, where one side of the dualism is valued higher than the other. Ecofeminism specifically highlights the dualism that maintains both the "ecological superiority of humans [over nature] and cultural superiority of men [over women]" [39, p. 309]. Ecofeminists approach these dualisms not by simply working towards valuing both sides equally, but rather we must dismantle the concept of the dualisms itself.

Thus, after acknowledging the values we hold, we must start to critique any underlying dualism. By dismantling the dualism, we can explore different ways of thinking. For example, one gendered dualism observed in engineering is the separation of 'hard' skills (i.e., theoretical formulas, mathematical calculations) and 'soft' skills (i.e., professional skills, sustainability) [8]. When dismantling this dualistic thinking, it is not about valuing the 'soft' skills equal to the 'hard' skills, but rather it is about dismantling the dualism entirely and understanding the essential interconnections between the two skillsets. One cannot exist without the other, they are essential to each other.

\subsection{Context is just as important as the numbers}

Contextual learning is essential to education for sustainability development, and enables students to make meaningful connections [40]. However, engineering practice problems are often simplified so that merely the technical is left and we remove all the social information. For example, in an upper year HVAC course, we may ask students to analyze the heating system and we don't consider how people are using the house. These social and contextual elements are just as important as the technical calculations.

\subsection{Intersectionality and engineering}

As discussed above, intersectionality is an understanding of the "inability of a single-axis framework to capture the lived experiences" of everyone and everything. [25, p. 63] Within ecofeminism, it is important to have an intersectional approach that considers not only the oppression of women and nature, but that we must achieve "liberation for all of those intersection points along these fault lines" [22, p. 71]. An ecofeminist analysis must not be limited to a solution for one situation, but must consider how each intersecting factor creates a unique set of circumstances in each situation. We must understand that the ecological crisis is a 'wicked problem' and "cannot be understood in a way which is not intersectional" [25].

Using a similar argument to Kings on the intersectionality of ecofeminism, here we argue that engineering is inherently intersectional. For example, when designing roads, there is an understanding that two climates which are wet cannot have the same road design if one is a wet, hot climate, and the other is a wet, cold climate. We cannot only consider the variable of precipitation, we must consider the intersection of precipitation and temperature in the asphalt design.

As shown in this example, intersectional thought is foundational to engineering design. However, we need to expand it to the way we think across engineering. For example, seatbelt designs have been notoriously critiqued. Regulatory testing meant seatbelts were only tested on fiftieth-percental male dummies, leading to women being $71 \%$ more likely to be injured, and $17 \%$ more likely to die in car accidents [41]. However, we cannot simply look at this problem and state that the solution is we need to start testing both male and female dummies. There are many intersectional factors to consider. For example, $62 \%$ of pregnant women in their third-trimester cannot wear a seatbelt properly, and women with larger breasts tend to wear seatbelts incorrectly leading to higher risk of injury [41].

At its core, engineering is intersectional. Within our engineering education classrooms, we can leverage this to consider how our content is presented to highlight and this intersectionality. All of the above recommendations should be done in a way that is intersectional. We must acknowledge our intersectional value systems, we must dismantle dualisms in a way that considers their intersectional connections, and the context for our problems must be intersectional.

\subsection{It's not going to be easy}

As part of bringing ecofeminism work into engineering, it is important to proactively consider the expected 
resistance. When people are resistant, they are unable to openly engage in dialogue, and thus we must set-up the learning environment in a way that encourages critical selfreflection and thoughtful conversations [42].

A part of the resistance to feminist work in engineering is that engineering culture operates with a presumed neutrality and meritocracy [12]. Meritocracies assume to not bias any group, to provide equal access to success for all groups, and to be free of politics. A belief in this meritocracy makes the system seem fair and that everyone has equal chance, as their success is based solely on 'merit'. This individualistic perspective makes it difficult for members of privileged groups difficult to consider they may have unfairly benefited from a system that works in their favour [42].

In engineering specifically, the emphasis on problem solving and application of the design process gives the misguided impression that engineering must therefore be based on academic ability in a way that is objective and value-neutral. As expressed by [12], "to raise concerns about inclusion or marginalization is not only out of step with the presumed political neutrality of engineering, but may be interpreted by some as threatening the objectivity of engineering itself." As feminist scholars, we therefore must intentionally approach the work knowing this resistance is present, and do our best to prevent and reduce the resistance, so that there is an openness from others to engage with the material.

In this paper, we will not expand further on specific advice for reducing resistance, however this is something that has been heavily studied in scholarship on social justice education. For example, in Chapter 5 of [42], the author provides 13 tips for preventing and reducing resistance, and 7 tips for responding to resistance. These types of approaches will be integrated into our design of pedagogies which bring ecofeminism into engineering curriculum.

\section{NEXT STEPS}

Using knowledge from ecofeminist scholarship, we have outlined suggestions on how to deconstruct elements of engineering that promote a masculine, elite, and individualist culture. By acknowledging the value systems underscoring engineering culture, dismantling the dualisms that exist, contextualizing engineering problem solving, and leveraging engineering intersectionality, we can begin to foster more inclusive spaces in our engineering classrooms. As educators, we want to develop future engineers who will design technologies that will build a better world, a world where all people, all species, and all of nature works in harmony together.

\section{Acknowledgements}

The authors wish to thank the Natural Sciences and Engineering Research Council, Alberta Innovates, and the Schulich School of Engineering for their generous support of this research.

\section{References}

[1] K. Beddoes, "Engineering education discourses on underrepresentation: Why problematization matters," Int. J. Eng. Educ., vol. 27, no. 5, pp. 1117-1129, 2011.

[2] L. J. Sax, M. Allison Kanny, J. A. Jacobs, H. Whang, D. S. Weintraub, and A. Hroch, Understanding the Changing Dynamics of the Gender Gap in Undergraduate Engineering Majors: 1971-2011, vol. 57, no. 5. Springer Netherlands, 2016.

[3] D. Riley, A. L. Pawley, J. Tucker, and G. D. Catalano, "Feminisms in Engineering Education: Transformative Possibilities Published by: The Johns Hopkins University Press Stable URL: http://www.jstor.org/stable/20628172 Feminisms in Engineering Education: Transformative Possibilities," vol. 21, no. 2, pp. 21-40, 2009.

[4] A. L. Pawley, "What counts as 'engineering': Toward a redefinition," in Engineering and Social Justice: In the University and Beyond, C. Baillie, A. L. Pawley, and D. Riley, Eds. Purdue University Press, 2012, pp. 59-85.

[5] J. Christman, "Where are all the women engineers? An insider's view of socialization and power in engineering educaiton.," The State University of New York at Buffalo, 2017.

[6] R. A. Martusewicz, "EcoJustice Education," EcoJustice Educ., 2014.

[7] T. Sikka, "Technofeminism and Ecofeminism: An Analysis of Geoengineering Reserach," in Ecofeminism in Dialogue, D. A. Vakoch and S. Mickey, Eds. Lanham, MD: Lexington Books, 2017.

[8] R. Rao, A. L. Pawley, S. R. Hoffmann, M. E. Cardella, and M. W. Ohland, "An ecofeminist grounded analysis of sustainability in engineering education: Skill set, discipline, and value," Int. J. Eng. Educ., vol. 29, no. 6, pp. 1472-1489, 2013.

[9] A. L. Pawley, "Universalized narratives: Patterns in how faculty members define 'engineering," J. Eng. Educ., vol. 98, no. 4, pp. 309-319, 2009.

[10] M. Savaria and K. Monteiro, "A Critical Discourse Analysis of Engineering Course Syllabi and Recommendations for Increasing Engagement among Women in STEM," J. STEM Educ. Innov. Res., vol. 18, no. 1, p. 92, 2017.

[11] L. Parson, "Are STEM syllabi gendered? A feminist critical discourse analysis," Qual. Rep., vol. 21, no. 1, pp. 102-116, 2016.

[12] C. Seron, S. Silbey, E. Cech, and B. Rubineau, "II am Not a Feminist, but..': Hegemony of a Meritocratic Ideology and the Limits of Critique Among Women in Engineering," 
Work Occup., vol. 45, no. 2, pp. 131-167, 2018.

[13] E. A. Cech, "Engineering Education for Social Justice: Critical Explorations and Opportunities, Philosophy of Enginering and Technology 10," Eng. Educ. Soc. Justice Crit. Explor. Oppor., pp. 67-84, 2013.

[14] A. C. Brown, I'm Still Here: Black dignity in a world made for whiteness. New York: Convergent Books, 2018.

[15] S. Harding, The Science Question in Feminism. Ithaca, New York: Cornell University Press, 1986.

[16] D. Haraway, "Situated Knowledges: The Science Question in Feminism and the Privilege of Partial Perspective," Fem. Stud., vol. 14, no. 3, p. 575, 1988.

[17] M. Sharma, "Applying feminist theory to medical education,” Lancet, vol. 393, no. 10171, pp. 570-578, 2019.

[18] F. Henwood, "WISE Choices? Understanding Occupational Decision-making in a Climate of Equal Opportunities for Women in Science and Technology," Gend. Educ., vol. 8, no. 2, pp. 199-214, 1996.

[19] A. Phipps, "Re-inscribing gender binaries: Deconstructing the dominant discourse around women's equality in science, engineering, and technology," Sociol. Rev., vol. 55, no. 4, pp. 768-787, 2007.

[20] K. Beddoes and M. Borrego, "Feminist theory in three engineering education journals: 1995-2008," J. Eng. Educ., vol. 100, no. 2, pp. 281-303, 2011.

[21] K. Beddoes, "Feminist methodologies and engineering education research," Eur. J. Eng. Educ., vol. 38, no. 1, pp. 107-118, 2013.

[22] K. Beddoes, "Practices of Brokering: Between STS and Feminist Engineering Education Research,” 2011.

[23] C. Kimberle, "Demarginalizing the Intersection of Race and Sex : A Black Feminist Critique of Antidiscrimination Doctrine, Feminist Theory and Antiracist Politics," Univ. Chicago Leg. Forum 1989, pp. 139-168, 1989.

[24] K. Davis, "Intersectionality as buzzword: A sociology of science perspective on what makes a feminist theory successful," Fem. Theory, vol. 9, no. 1, pp. 67-85, 2008.

[25] A. E. Kings, "Intersectionality and the changing face of ecofeminism," Ethics Environ., vol. 22, no. 1, pp. 63-87, 2017.

[26] J. Bile, "The Rhetorics of Critical Ecofeminism: Conceptual Connection and Reasoned Response," in Ecofeminism and Rhetoric: Critical Perspectives on Sex, Technology, and Discourse, D. A. Vakoch, Ed. Berghahn Books, 2011, pp. 1-37.
[27] J. Seager, Earth Follies: Coming to Feminist Terms with the Global Environmental Crisis. New York: Routledge, 1993.

[28] C. Herles, "Muddying the Waters Does Not Have to Entail Erosion: Ecological Feminist Concerns with Purity," Int. J. Sex. Gend. Stud., vol. 5, no. 2, pp. 109-123, 2000.

[29] J. E. Romberger, "Ecofeminist Ethics and Digital Technology: A Case Study of Microsoft Word," in Ecofeminism and Rhetoric: Critical Perspectives on Sex, Technology, and Discourse2, D. A. Vakoch, Ed. Berghahn Books, 2011, pp. 117-143.

[30] K. L. Gunckel, "Queering Science for All Probing Queer Theory in Science Education," J. Curric. Theor., vol. 25, no. 2, pp. 62-75, 2009.

[31] J. Seager, "Rachel Carson Died of Breast Cancer: The Coming of Age of Feminist Environmentalism," Gend. Sci. New Issues, vol. 28, no. 3, pp. 945-972, 2003.

[32] K. J. (Ed. . Warren, Ecofeminism: Women, Culture, Nature. Bloomington: Indiana University Press, 1997.

[33] C. Merchant, Radical Ecology: The Search for a Livable World, Second. New York: Routledge, 2005.

[34] C. A. Stabile, Feminism and the Technological Fix. New York: Manchester University Press, 1994.

[35] J. A. Leydens and J. C. Lucena, Engineering Justice: Transforming Engineering Education and Practice. Hoboken, NJ: John Wiley \& Sons, 2018.

[36] J. Kabo and C. Baillie, "Engineering and Social Justice: How to help students cross the threshold," vol. 4, no. 2, pp. 126-146, 2009.

[37] E. Margolis, The hidden curriculum in higher education. Psychology Press, 2001

[38] C. Baillie and E. P. Douglas, "Confusions and conventions: Qualitative research in engineering education," J. Eng. Educ., vol. 103, no. 1, pp. 1-7, 2014.

[39] C. Mallory, "What is Ecofeminist Political Philosophy? Gender, Nature and the Political," Environ. Ethics, vol. 32, no. 3, pp. 305-322, 2010.

[40] A. Guerra, "Integration of sustainability in engineering education: Why is PBL an answer?," Int. J. Sustain. High. Educ., vol. 18, no. 3, pp. 436-454, 2017.

[41] C. C. Perez, Invisible Women: Data Bias in a World Designed for Men. New York, NY: Abrams Press, 2019.

[42] D. J. Goodman, Promoting Diversity and Social Justice: Educating People from Privileged Groups. SAGE Publications, 2001. 